2018-09-01

\title{
Co-located wave-wind farms for improved O\&M efficiency
}

\author{
Astariz, S
}

http://hdl.handle.net/10026.1/11627

Ocean and Coastal Management

Elsevier

All content in PEARL is protected by copyright law. Author manuscripts are made available in accordance with publisher policies. Please cite only the published version using the details provided on the item record or document. In the absence of an open licence (e.g. Creative Commons), permissions for further reuse of content should be sought from the publisher or author. 


\section{CO-LOCATED WAVE-WIND FARMS FOR IMPROVED O\&M EFFICIENCY}

\section{S. ASTARIZ ${ }^{*}$, A. VAZQUEZ ${ }^{1}$, M. SÁNCHEZ ${ }^{1}$, R. CARBALLO $^{1}$, G. IGLESIAS $^{2}$}

${ }^{1}$ University of Santiago de Compostela, Spain, "corresponding author: sharay.astariz@usc.es

${ }^{2}$ Plymouth University, UK

If ocean energy is to become a viable alternative to fossil fuels, its competitiveness visà-vis other energy sources must be enhanced. Furthermore, marine space is scarce, and its use should be optimised. On these grounds, the combination of offshore wind and wave energy in the same marine space (co-located) holds promise. This paper focuses on the benefits in terms of O\&M efficiency that ensue from the so-called shadow effect - the reduction in significant wave height in the inner part of the farm thanks to the presence of the wave energy converters (WECs) - in the form of enlarged weather windows. This investigation is carried out through a case study of four wind farms in the North Sea, including a sensitivity analysis in terms of: (i) location (depth and distance from the coast), (ii) sea climate, and (iii) wind farm layout. Real (observed) sea conditions are considered, and a third-generation wave model (SWAN) is implemented on a high-resolution grid. We find that the combination of wave and offshore wind energy increases the accessibility for O\&M tasks in all the cases considered, leading to accessibility values of up to $82 \%$.

KEYWORDS: Wave energy; Wind energy; Co-located wind-wave farm; Weather windows for O\&M; Shadow effect. 


\section{INTRODUCTION}

27 Marine energy is one of the most promising alternatives to fossil fuels due to the enormous energy resource available. However, it is often considered uneconomical and difficult. Combining this promising marine renewable with a more consolidated renewable like offshore wind energy is a solution of great interest to enhance marine energy competitiveness [1]. According to the degree of connectivity between the offshore wind turbines and Wave Energy Converters (WECs) combined wave-wind systems can be classified into: co-located, hybrid and islands systems [2]. According to the current state of development of both technologies, the co-location of WECs into a conventional offshore wind farm is regarded as the best option (2009/28/EC) [3], which combines an offshore wind farm and a WEC array with independent foundation systems but sharing: the same marine area, grid connection, O\&M equipment, etc.

There are many synergies between both renewables [4], such as the more sustainable use of the marine resource, the reduction in the intermittency inherent to renewables or the opportunity to reduce costs by sharing some of the most expensive elements of an offshore project. In addition to these powerful reasons there are a number of technology synergies between wave and wind systems which make their combination even more attractive, and this paper focuses on one of them: the so-called shadow effect, i.e. the reduction in the significant wave height in the inner part of the farm. The operational limit of workboats (the most cost-effective access system for maintenance tasks) is a significant wave height of $1.5 \mathrm{~m} \mathrm{[5]}$; when this threshold is exceeded delays in maintenance and repairs ensue, increasing downtime - with the associated costs. Thus, while modern onshore wind turbines present accessibility levels of 97\% [6], this level can be significantly reduced in offshore installations. 
50 On this basis, the aim of this study is to analyse the wave height reduction achieved by

51 deploying co-located WECs and the influence of the layout in the results. This purpose

52 is carried out through various cases studies. Four wind farms currently in operation

53 (Alpha Ventus, Bard 1, Horns Rev 1 and Lincs) are taken as baseline scenarios to

54 analyse theinfluence of the wind farm characteristics, such as the location, the proximity

55 to coast and the layout, on the results obtained. A state-of-the-art, third generation wave

56 propagation model (SWAN) implemented on a high-resolution computational grid is

57 applied and real sea conditions are considered.

\section{METHODOLOGY}

\subsection{Case study}

The study of the shielding effect of the WECs barrier in an offshore wind farm was

61 carried out by considering four wind farms currently in operation at the North Sea: Bard

62 1, Horns Rev 1 and Lincs, whose locations and characteristics are presented in Figure 1

63 and Table 1, respectively. These four wind farms encompass a wide variety of

64 characteristics on which to establish a comparative analysis.

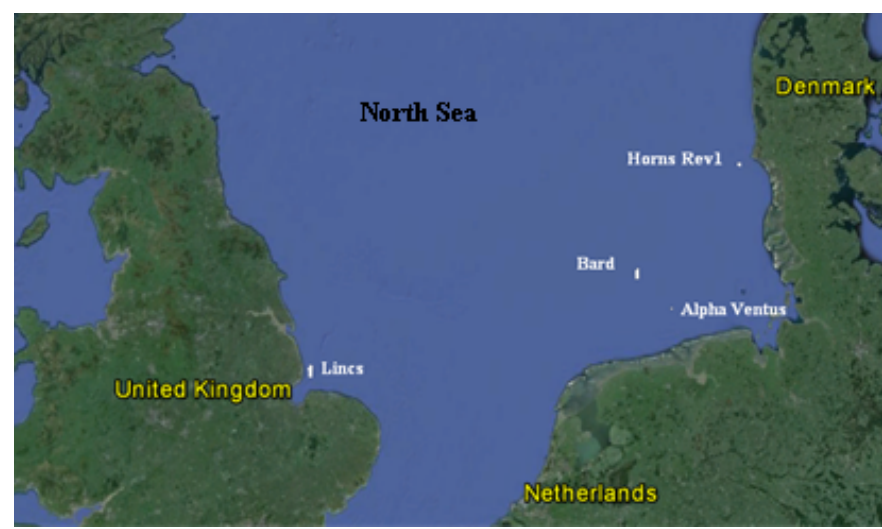

Figure. 1. Location of the four wind farms used in this study: Alpha Ventus, Bard 1, Horns Rev 1 and Lincs. 
Table 1. Characteristics of the Wind Farms

\begin{tabular}{cccccc}
\hline Wind farm & Depth $(\mathrm{m})$ & $\begin{array}{c}\text { Distance from } \\
\text { shore }(\mathrm{km})\end{array}$ & $\begin{array}{c}\text { Installed capacity } \\
(\mathrm{MW})\end{array}$ & $\begin{array}{c}\text { Number } \\
\text { turbines }\end{array}$ & $\begin{array}{c}\text { Area } \\
\left(\mathrm{km}^{2}\right)\end{array}$ \\
\hline $\begin{array}{c}\text { Alpha } \\
\text { Ventus }\end{array}$ & $33-45$ & 56 & 60 & 12 & 4 \\
Bard 1 & $39-41$ & $90-101$ & 400 & 80 & 59 \\
$\begin{array}{c}\text { Horns Rev } \\
1\end{array}$ & $6-14$ & $14-20$ & 160 & 80 & 21 \\
Lincs & $8-16$ & 8 & 270 & 75 & 41 \\
\hline
\end{tabular}

72 Horns Rev 1 has been characterised previously. The Alpha Ventus wind farm is composed by 12 turbines: 6 AREVA turbines with a tripod substructure and 6 Repower $5 \mathrm{M}$ turbines with a jacket-frame substructure with a spacing between turbines of around $800 \mathrm{~m}$ [11]. For their part, Bard 1 is composed of $805 \mathrm{MW}$ turbines (Bard 5.0) on tripod substructures [12], and Lincs of 75 3.6 MW Siemens turbines on monopiles [13]. In Alpha Ventus and Horns Rev 1 the wind turbines are arranged on a Cartesian grid, whereas in Bard 1 and Lincs they are not organised in clearly defined rows, and the distance between turbines varies in each case. As regards the sea climate, wave buoy measurements were used, and the main wave climate parameters are shown in Table 2: $H_{s}$ is the significant wave height, $T_{m 01}$ the mean wave period, $\theta$ the mean wave direction, $U_{w}$ the most frequent wind speed at $10 \mathrm{~m}$, and $D_{w}$ the corresponding wind direction.

Table 2. Wave and Wind Conditions at the Wind Farm Site.

\begin{tabular}{cccccc}
\hline Wind farm & $H_{s}(\mathrm{~m})$ & $T_{m o l}(\mathrm{~s})$ & $\theta\left(^{\mathrm{o}}\right)$ & $U_{w}\left(\mathrm{~ms}^{-1}\right)$ & $D_{w}\left(^{\mathrm{o}}\right)$ \\
\hline Alpha Ventus & 1.5 & 4.6 & 330 & 10 & $210-240$ \\
Bard 1 & $0.8-1.5$ & 4.0 & 320 & 9.2 & 330 \\
HornsRev 1 & $0.8-1$ & $4-4.6$ & $230-340$ & 9.7 & $225-315$ \\
Lincs & $0.6-0.7$ & $3.4-4.4$ & $0-15$ & 8.4 & $10-70$ \\
\hline
\end{tabular}

84 Having defined the wind farms, a Peripherally Distributed Array (PDA) was selected 85 for the co-location of the WECs. The PDA is a type of co-located system which 86 combines both wind and wave arrays by positioning the WECs at the periphery of the 87 offshore wind farm.. The WEC used in this analysis, is the WaveCat: a floating offshore 
101

102

103

104

105

106

107

108

109

WEC whose principle of operation is wave overtopping, and with a length overall of 90 $\mathrm{m}$. The minimum distance between devices is $2.2 D$, where $D=90 \mathrm{~m}$ is the distance between the twin bows of a single WaveCat WEC [10].

Two co-located WECs layouts (Table 3) were proposed taking into account the wind farm layouts, the wave climate, and the results of previous studies $[14,15]$. In the first case (Figure 2a), the co-located WECs configuration consists of two main rows of WECs with a spacing of $198 \mathrm{~m}$ orientated towards the prevailing wave direction, and other rows of WECs at an angle of $45^{\circ}$ to face secondary wave directions and thus protect a larger wind farm area. With the second configuration (Figure 24b) the aim is to check if deploying WECs in an arc can lead to a wave height reduction similar to that obtained with an angular layout with fewer WECs.

Table 3. Total Number of Co-located WECs and the Rate Between the Total Number of WECs and Wind Turbines $(r)$.

\begin{tabular}{ccccc}
\hline \multirow{2}{*}{ Wind farm } & \multicolumn{2}{c}{ Layout in angle } & \multicolumn{2}{c}{ Layout in arc } \\
\cline { 2 - 5 } & Total & $r$ & Total & $r$ \\
\hline Alpha Ventus & 34 & 2.83 & 32 & 2.67 \\
Bard 1 & 79 & 0.99 & 79 & 0.99 \\
Horns Rev 1 & 55 & 0.69 & 53 & 0.66 \\
Lincs & 81 & 1.01 & 80 & 1 \\
\hline
\end{tabular}
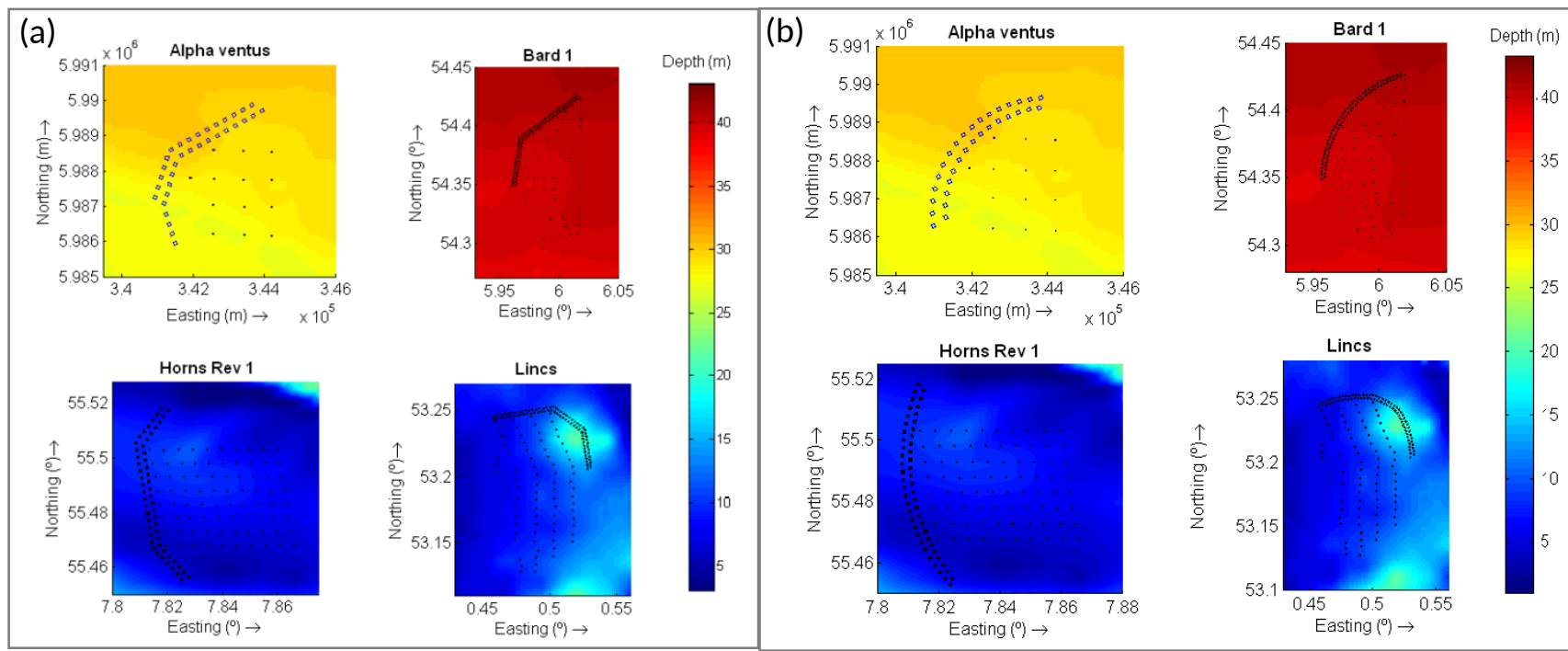

Figure 2. Co-located wind farm layouts with WECs: (a) at an angle. (b) in arc. 
114 The assessment of the wave height reduction in the wind farm caused by the co-located

115 WECs was carried out using a third-generation numerical wave model, SWAN

116 (Simulating WAves Nearshore), which was successfully used in previous works [16-18]

117 to model the impact of a wave farm on nearshore wave conditions. The evolution of the

118 wave field is described by the action balance equation, Equation (1), which equates the

119 propagation of wave action density in each dimension balanced by local changes to the

120 wave spectrum:

$$
\frac{\partial}{\partial t} N+\frac{\partial}{\partial x} c_{x} N+\frac{\partial}{\partial y} c_{y} N+\frac{\partial}{\partial \sigma} c_{\sigma} N \frac{\partial}{\partial \theta} c_{\theta} N=\frac{S_{t o t}}{\sigma}
$$

122

where $t$ is time (s), $c_{x}$ and $c_{y}$ are spatial velocities in the $x$ and $y$ components $\left(\mathrm{ms}^{-1}\right), c_{\theta}$ and $c_{\sigma}$ are rates of change of group velocity which describe the directional $(\theta)$ rate of turning and frequency $(\sigma)$ shifting due to changes in currents and water depth, $\mathrm{N}$ is wave action density spectrum, and $S_{t o t}$ is the energy density source terms which describe local changes to the wave spectrum.

In this work the model was implemented in the so-called nested mode, with two computational grids (Table 4) in order to obtain high-resolution results without excessive computational cost. The bathymetric data, from the UK's data centre Digimap, were interpolated onto this grid.

Table 4. Surface Area Covered by the Computational Grids and Grid Size.

\begin{tabular}{lcccc}
\hline \multirow{2}{*}{ Wind farm } & \multicolumn{2}{c}{ Coarse grid } & \multicolumn{2}{c}{ Nested grid } \\
\cline { 2 - 5 } & Area $(\mathrm{km})$ & Resolution $(\mathrm{m})$ & Area $(\mathrm{km})$ & Resolution $(\mathrm{m})$ \\
\hline Alpha Ventus & $40 \times 30$ & $100 \times 100$ & $8.5 \times 8.5$ & $17 \times 17$ \\
Bard 1 & $111 \times 111$ & $222 \times 222$ & $18 \times 22$ & $40 \times 40.4$ \\
Horns Rev1 & $42 \times 32$ & $70 \times 80$ & $9.35 \times 9$ & $17 \times 20$ \\
Lincs & $119 \times 111$ & $170 \times 159$ & $14.4 \times 18.2$ & $32 \times 33$ \\
\hline
\end{tabular}


132 The wind turbines were represented in the model by a transmission coefficient, whose 133 value can vary in theory from $0 \%$ (i.e., $100 \%$ of incident wave energy absorbed) to $134100 \%$. This technique was used in previous studies to represent single wind turbines [19] 135 or wind farm arrays [20], and arrays of WECs [21]. In this study, the transmission 136 coefficient of the offshore wind turbines was calculated by [22]:

$$
c_{t}=4\left(\frac{d}{H_{i}}\right) E\left[-E+\sqrt{E^{2}+\frac{H_{i}}{2 d}}\right]
$$

$$
E=\frac{C_{d}\left(\frac{b}{D+b}\right)}{\sqrt{1-\left(\frac{b}{D+b}\right)^{2}}}
$$

where $d$ is depth (m), $H_{i}$ is incident significant wave height $(\mathrm{m}), D$ is the pile diameter (m), $b$ is the pile spacing (m), and $C_{d}$ is the drag coefficient of the piles (1.0 for a smooth pile).

As for the co-located WECs, they have also been modelled as obstacles characterised by a transmission coefficient, as in previous works [23-25]. The value of this coefficient is derived from the results of the physical modelling of the WaveCat [26].

\subsection{Impact Indicators}

To compare the results achieved in the proposed co-located farms a series of impact indicators were defined: (i) the significant wave Height Reduction within the Farm $(H R F)$, (ii) the significant wave Height Reduction within the $j$-th Area of wind turbines $(H R A j)$, and (iii) the increase in access time for O\&M $\left(\Delta T_{O \& M}\right)$. The $H R F$ and $H R A_{j}$ indices provide information about the average wave height reduction within the wind

151 farm and the wave recovery with increasing distance from the WECs, respectively, and were calculated by Equations (4) and (5). 


$$
\operatorname{HRF}(\%)=\frac{100}{n} \sum_{i=1}^{n} \frac{1}{\left(H_{s, b}\right)_{i}}\left[\left(H_{s, b}\right)_{i}-\left(H_{s, W}\right)_{i}\right]
$$

154 where the index $i$ designates a generic turbine of the wind farm, $n$ is the total number of 155 turbines, $\left(H_{s, b}\right)_{i}$ is the significant height incident on the $i$-th turbine in the baseline scenario (without WECs), and $\left(H_{s, W}\right)_{i}$ is the significant height incident on the $i$-th turbine with co-located WECs.

$$
H R A_{j}(\%)=\frac{100}{m} \sum_{i=1}^{m} \frac{1}{\left(H_{s, b}\right)_{i}}\left[\left(H_{s, b}\right)_{i}-\left(H_{s, W}\right)_{i}\right]
$$

where the index $i$ denotes a generic turbine of the $j$-th area of the wind farm, and $m$ is the number of turbines in the $j$-th area. In the case of Alpha Ventus and Horns Rev 1 each $j$-th area corresponds to a vertical row of turbines numbered from east to west, $j=$ 1, 2, 3 in Alpha Ventus and $j=1,2 \ldots 10$ in Horns Rev 1. However, in the other two wind farms, due to the less orderly layout, the division was made into different areas with a similar number of turbines, and numbered according to the mean wave direction (Figure 3).

The $\Delta T_{O \& M}$ non-dimensional index allows the assessment of the increase in the timeframe accessibility to the wind turbines thanks to the co-located WECs, and can be computed from Equation (6).

$$
\Delta T_{O \& M}(\%)=\frac{T_{W}-T_{b}}{T_{W}} \times 100
$$

where $T_{W}$ and $T_{b}$ are the total number of hours per year when $H_{s}$ within the wind farm is lower or equal to $1.5 \mathrm{~m}$ with co-located WECs and in the baseline scenario, respectively. 

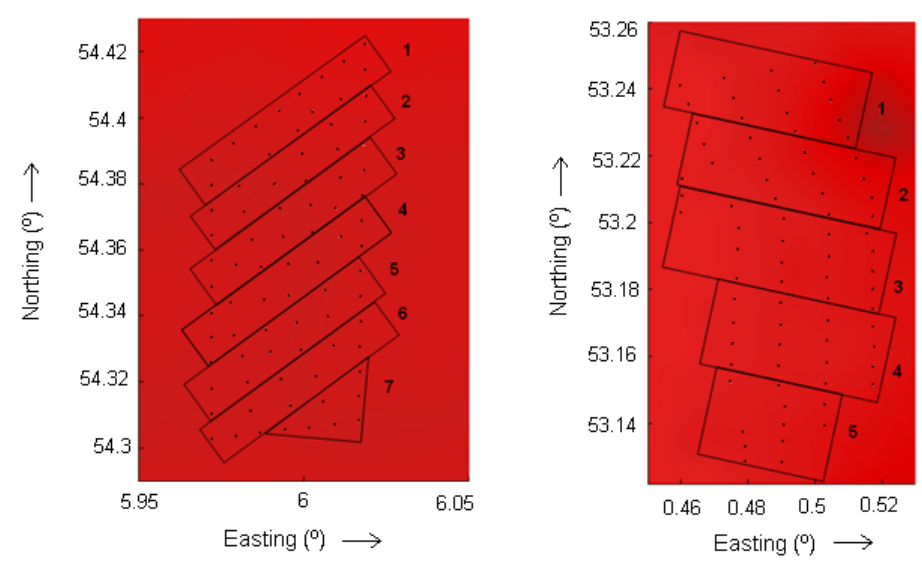

Figure 3. The $j$-th areas into which Bard 1 (left) and Lincs (right) were divided to calculate the $H R A_{j}$ index.

\section{RESULTS AND DISCUSSION}

The proper functioning of the nearshore wave propagation model was validated with wave buoy data. In all cases, a good correlation was observed between the simulated and measured time series, as shown by the values of $R^{2}$ and RMSE, always higher than 0.93 and lower than $0.36 \mathrm{~m}$, respectively.

As regards the wave height reduction achieved throughout the farm $(H R F)$, it ranged between 13\% and 19\% (Table 5) and was always larger for the layouts with WECs deployed at an angle than for those in arc, although the difference between the results of both configurations was small (between 1 and 2\%). Comparing the results between wind farms (Table 5), the best values were obtained for Bard 1, where a good interception of the incoming waves was achieved for the two layouts of co-located farms (Figure 4). These results were followed very closely by those obtained for Alpha Ventus and Horns Rev 1, whereas the wave height reduction achieved at Lincs was smaller. This was due to three main factors. First, the wind farm layout - this farm has a slightly elongated shape. Second, the wave direction has a greater variability than in the other case studies, and the farm remained unprotected against waves from secondary directions (Figure 5). For this reason a larger number of WECs would be required on 
the east side of the farm to achieve better results; however, this would imply an important increase in the ratio between the number of WECs and wind turbines, raising the final cost of the co-located farm. Third, the wave climate in this park, which was milder than in the other farms and, therefore, less wave energy could be extracted by the co-located WECs.

Table 5. HRF (\%) Values achieved with co-located WECs deployed in angle or in arc based on the annual data series.

\begin{tabular}{cccc}
\hline Wind farm & Layout & $N_{W E C s}$ & HRF $(\%)$ \\
\hline \multirow{2}{*}{ Alpha Ventus } & in angle & 34 & 18 \\
& in arc & 32 & 17 \\
\hline \multirow{2}{*}{ Bard 1 } & in angle & 79 & 19 \\
& in arc & 79 & 17 \\
\hline \multirow{2}{*}{ Horns Rev 1 } & in angle & 55 & 17 \\
& in arc & 53 & 15 \\
\hline \multirow{2}{*}{ Lincs } & in angle & 81 & 14 \\
& in arc & 80 & 13 \\
\hline
\end{tabular}
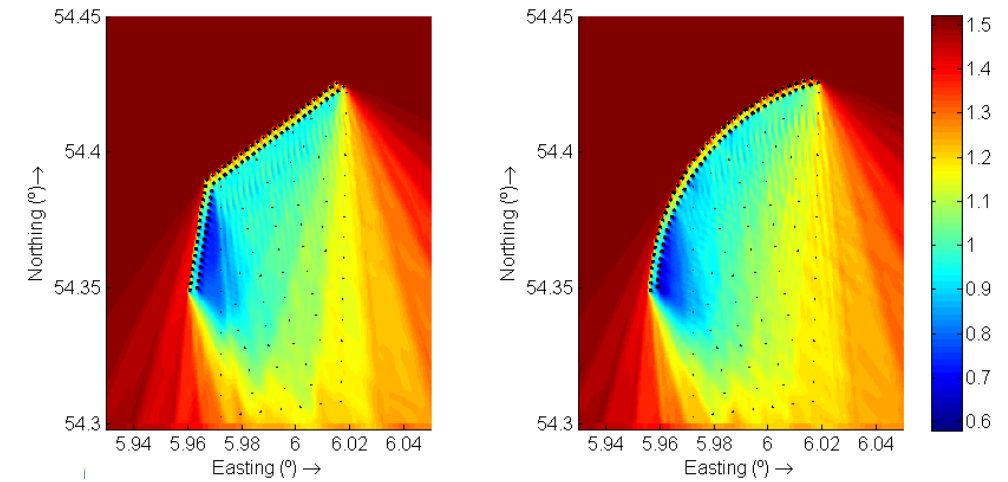

Figure 4. Wave height reduction obtained with co-located WECs at Bard 1 under a sea state with: $H s=1.71 \mathrm{~m}, T p=6.09 \mathrm{~s}$ and $\theta=230^{\circ}$. The colour scale represents the significant wave weight, $H s(\mathrm{~m})$.
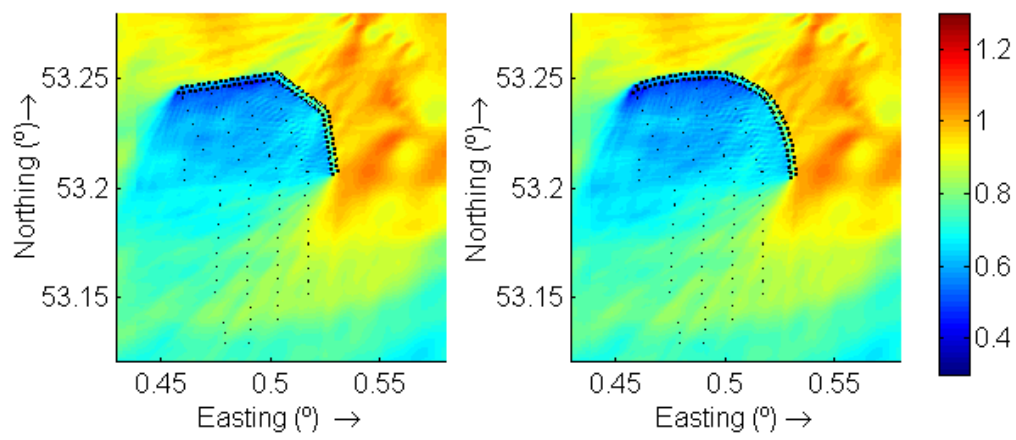

Figure 5. Wave height reduction due to co-located WECs at Lincs under a sea state with: $H s=1.18 \mathrm{~m}, T p=6.03 \mathrm{~s}$ and $\theta=60^{\circ}$. The colour scale represents the significant wave weight, $H s(\mathrm{~m})$. 
211 Furthermore, the results of Horns Rev 1 are particularly interesting since they were

212 similar to those of the best scenario, even though the ratio between number of WECs

213 and wind turbines in Horns Rev 1 is much lower than in the other cases - an important

214 consideration for the economic assessment. The explanation lies in the geometry of the

215 wind farms: the layout of Horns Rev 1 is close to a square, whereas Bard 1 or Lincs

216 have a more elongated shape and therefore require more WECs for a similar degree of

217 shelter.

218 Apart from the average wave height reduction in the farm $(H F R)$, it is interesting to 219 analyse the spatial variation in the wave height reduction through its value in different sections $\left(H R A_{j}\right)$, since the best WECs layout should achieve not only high values of $H F R$ but also a fairly homogenous reduction throughout the farm. As may be expected, in all case studies the tendency was for the highest reduction to occur immediately behind the WECs, with $H R A_{j}$ decreasing with increasing distance from the co-located WECs (Figure 6). However, the wave height reduction was significant even as the distance from the WECs increased. As with the wave height reduction for the entire farm, greater values of $H R A_{j}$ were obtained generally for configurations with WECs deployed at an angle rather than in arc. Lincs presented the highest difference between $H R A_{j}$ values in the first and second area of turbines (around $23 \%$ ), and was also the case with the smallest difference between the wave height reduction with co-located WECs in angle or in arc. Therefore, it may be concluded that in the case of wind farms with a milder wave climate, like Lincs, wave heights are restored more quickly behind the

232 WEC barrier, and the choice between angular or arched layouts for the co-located WECs does not have a significant influence on the enlargement of the weather windows for O\&M. 
235 As regards the accessibility to the wind turbines, it was below $82 \%$ for all the wind 236 farms analysed, which corresponds to availability values below 90\%. Nevertheless, an 237 important increase of the accessibility was achieved by deploying co-located WECs 238 along the periphery of the farm in the four case studies (Table 6). More specifically, the 239 results for Alpha Ventus and Bard 1 were very similar, the accessibility increased $240\left(\Delta T_{O \& M}\right)$ by $17-18 \%$, whereas in Horns Rev 1 this increased by $13-15 \%$ and in Lincs by $8 \%$.
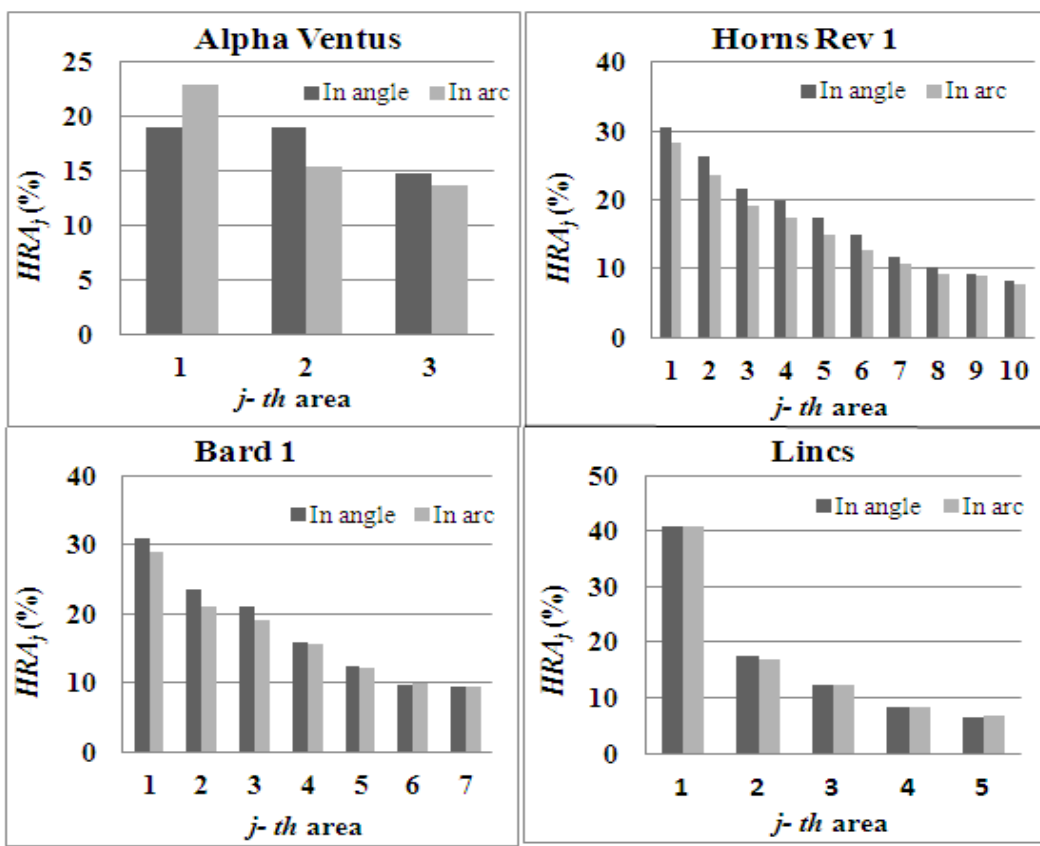

Figure 6. HRAj (\%) values with co-located WECs deployed in angle or in arc based on the annual data series data.

Table 6. Accessibility and $\Delta \mathrm{T}_{\mathrm{O} \& \mathrm{M}}$ Values for the co-located farms considered.

\begin{tabular}{cccc}
\hline Wind farm & Layout & Accessibility $(\%)$ & $\Delta T_{O \& M}(\%)$ \\
\hline \multirow{2}{*}{ Alpha Ventus } & in angle & 82.3 & 18.0 \\
\cline { 2 - 4 } & in arc & 82.2 & 17.8 \\
\hline \multirow{2}{*}{ Bard 1 } & in angle & 69.7 & 18.2 \\
\cline { 2 - 4 } & in arc & 69.0 & 17.5 \\
\hline \multirow{2}{*}{ Horns Rev 1 } & in angle & 70.9 & 15.6 \\
\cline { 2 - 4 } & in arc & 69.5 & 13.9 \\
\hline \multirow{2}{*}{ Lincs } & in angle & 81.3 & 8.9 \\
\cline { 2 - 4 } & in arc & 81.1 & 8.6 \\
\hline
\end{tabular}




\section{CONCLUSIONS}

249 The objective of this study was to analyse and compare the wave height reduction and the enlarged weather windows that can be achieved in the inner part of a wind farm by deploying WECs as a barrier. For these purposes, a case study in the North Sea was carried out, considering four wave farms with different characteristics in terms of location and configuration. Two co-located farm layouts were analysed for each of them in order to find the configuration that optimises the shielding effect of the WECs.

All the case studies were conducted using real wave conditions and a third-generation wave model (SWAN). It was found that relevant reductions in the significant wave height were achieved in all cases (over 13.5\%), resulting in significant enlargements of the weather windows for O\&M. Indeed, in the case of Alpha Ventus and Lincs, values around $82 \%$ were obtained for the accessibility, which would ensure an availability of the turbines of $90 \%$ or higher. With regard to the influence of the co-located farm layout on the results, the arrays with small spacings between converters achieved the best results in terms of significant wave height reduction. Moreover, the best results were obtained for co-located farms in which the WECs face both the prevailing and secondary wave directions, either with WECs deployed forming an angle or arc. Concerning the influence of the wind farm location, it was found that the proximity to land is not favourable in terms of deploying co-located WECs, for it implies lower water depths and, typically, a milder wave climate, and consequently less available wave energy to be extracted by the WECs. As for the wind farm layout, it was found that the greatest reduction in significant wave height, i.e. the most pronounced shadow effect, was achieved for wind farms with square-like geometries, like Horns Rev. 1. tasks as determined by the significant wave height are increased in a relevant manner 
273 by the energy-absorbing WECs; and (ii) analysed the main aspects to be taken into 274 account in deploying co-located wave-wind for this purpose.

This work was carried out in the framework of the Marie Sklodowska Curie Individual supported by FPU grant 13/03821 of the Spanish Ministry of Education, Culture and Sport. The authors are grateful to: the Bundesamt für Seeschifffahrt und Hydrographie (BSH) of Germany for providing access to the bathymetric and wave data from the FINO 1, 2 and 3 research platforms; to the UK's Centre for Environment, Fisheries and Aquaculture Science (CEFAS) for the wave data from the Dowsign buoy; to the Horns Rev wind farm for the resource data of the site; and to the European Marine Observation and Data Network (EMODnet) for the bathymetric data of the North Sea.

\section{REFERENCES}

[1] Astariz, S. and G. Iglesias, 2014. Wave energy vs. Other energy sources: a reassessment of the economics. International Journal of Green Energy, In Press.

290 [2] Pérez-Collazo, C., D. Greaves and G. Iglesias, 2015. A review of combined wave and offshore wind energy. Renewable and Sustainable Energy Reviews, 42 (0): 141-153. [3] Directive 2009/28/EC of the European Parliament and of the Council of 23 April 2009 on the promotion of the use of energy from renewable sources and amending and subsequently repealing Directives 2001/77/EC and 2003/30/EC (Text with EEA relevance)

296 [4] Pérez-Collazo, C., M. M. Jakobsen, H. Buckland and J. Fernández-Chozas, 2013. 297 Synergies for a wave-wind energy concept. Frankfurt, Germany.

298 [5] Astariz, S., C. Perez-Collazo, J. Abanades and G. Iglesias, 2015. Co-located wind299 wave farm synergies (Operation \& Maintenance): A case study. Energy Conversion and 300 Management, 91 (0): 63-75. 
[6] Millar, D. L., H. C. M. Smith and D. E. Reeve, 2007. Modelling analysis of the sensitivity of shoreline change to a wave farm. Ocean Engineering, 34 (5-6): 884-901.

[7] Bussel, G. J. W. v. and M. B. Zaaijer, 2001. Reliability, Availability and Maintenance aspects of large-scale offshore wind farms, a concepts study. Brussels, Belgium.

[8] Kenny, J. P., 2009. SW Wave Hub-Meteocean design basis, METOC. 29: 111.

[9] TUDelft, 2006. Wind farm optimization, Horns Rev: optimization of layout for wake losses SET MSc course wind energy. T. U. Eindhoven.

[11] Beels, C., P. Troch, J. P. Kofoed, P. Frigaard, J. Vindahl Kringelum, P. Carsten Kromann, M. Heyman Donovan, J. De Rouck and G. De Backer, 2011. A methodology for production and cost assessment of a farm of wave energy converters. Renewable Energy, 36 (12): 3402-3416.

[12] 4coffshore, June 2014. Bard wind farm, [Online]. Available: http://www.4coffshore.com/windfarms/bard-offshore-1-germany-de23.html

$317 \quad[13 / 06 / 2015]$.

[13] 4coffshore, June 2014. Lincs wind farms, [Online]. Available: http://www.4coffshore.com/windfarms/lincs-united-kingdom-uk13.htm [13/06/2015]. Retrieved June 2014.

[14] Astariz, S., \& Iglesias, G. (2016). Output power smoothing and reduced downtime period by combined wind and wave energy farms. Energy, 97: 69-81

[15] Astariz, S., Perez-Collazo, C., Abanades, J., \& Iglesias, G. (2015). Co-located wave-wind farms: Economic assessment as a function of layout. Renewable Energy, 83: 837-849.

[16] Abanades, J., D. Greaves and G. Iglesias, 2014. Wave farm impact on the beach profile: A case study. Coastal Engineering, 86 (0): 36-44.

[17] Palha, A., L. Mendes, C. J. Fortes, A. Brito-Melo and A. Sarmento, 2010. The impact of wave energy farms in the shoreline wave climate: Portuguese pilot zone case study using Pelamis energy wave devices. Renewable Energy, 35 (1): 62-77.

[18] Smith, H. C. M., C. Pearce and D. L. Millar, 2012. Further analysis of change in nearshore wave climate due to an offshore wave farm: An enhanced case study for the Wave Hub site. Renewable Energy, 40 (1): 51-64.

[19] Ponce de Leon, S., Bettencourt, J.H., Kjerstad, N., 2011. Simulation of Irregular Waves in an Offshore Wind Farm with a Spectral Wave Model. Continental Shelf Res., 3117.

[20] ETSU, 2002. Potential effects of offshore wind developments on coastal processes. ETSU W/35/00596/00/REP. P. b. A. a. METOC, [Online]. Available: http://www.offshorewindenergy.org/reports/report_002.pdf [13/06/2015].

340 [21] Astariz, S., C. Perez-Collazo, J. Abanades and G. Iglesias, 2015. Towards the 341 optimal design of a co-located wind-wave farm. Energy, In Press. 
344 [23] Beels, C., Troch, P., De Backer, G., Vantorre, M., \& De Rouck, J. (2010). 345 Numerical implementation and sensitivity analysis of a wave energy converter in a 346 time-dependent mild-slope equation model. Coastal Engineering, 57(5): 471-492.

347 [24] Bento, A. R., Rusu, E., Martinho, P., \& Soares, C. G. (2014). Assessment of the 348 changes induced by a wave energy farm in the nearshore wave conditions. Computers \& 349 Geosciences, 71: 50-61.

350 [25] Millar, D. L., Smith, H. C. M., \& Reeve, D. E. (2007). Modelling analysis of the 351 sensitivity of shoreline change to a wave farm. Ocean engineering, 34(5): 884-901.

352 [26] Fernandez, H., G. Iglesias, R. Carballo, A. Castro, J. A. Fraguela, F. Taveira-Pinto 353 and M. Sanchez, 2012. The new wave energy converter WaveCat: Concept and 354 laboratory tests. Marine Structures, 29 (1): 58-70. 


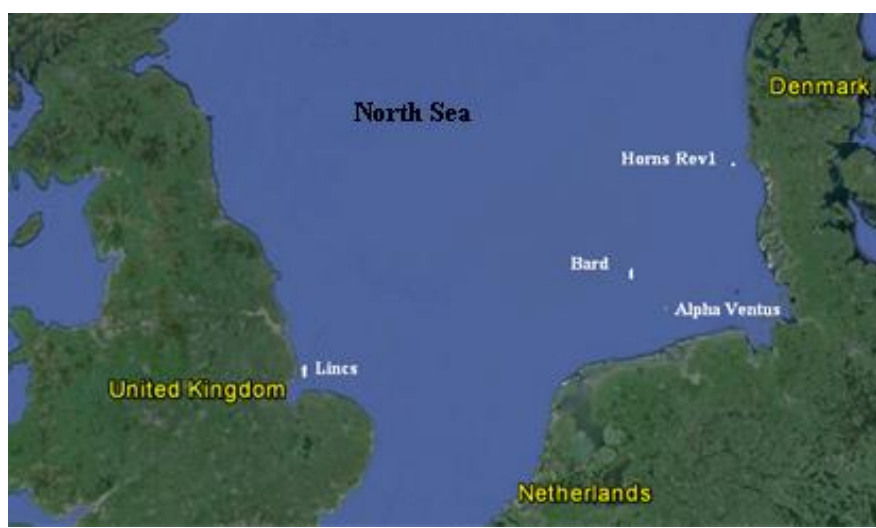

Figure 1. Location of the four wind farms used in this study: Alpha Ventus, Bard 1, Horns Rev 1 and Lincs. 


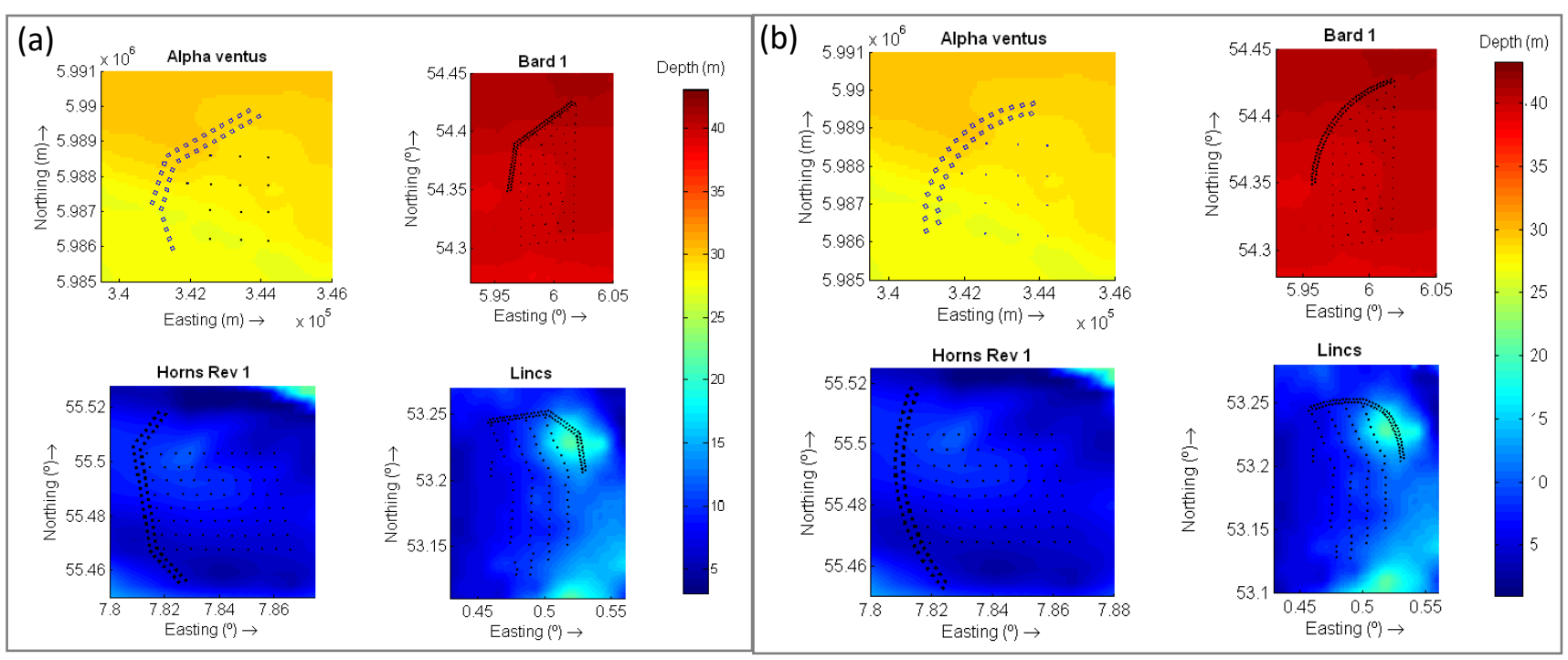

Figure 2. Co-located wind farm layouts with WECs: (a) at an angle. (b) in arch. 

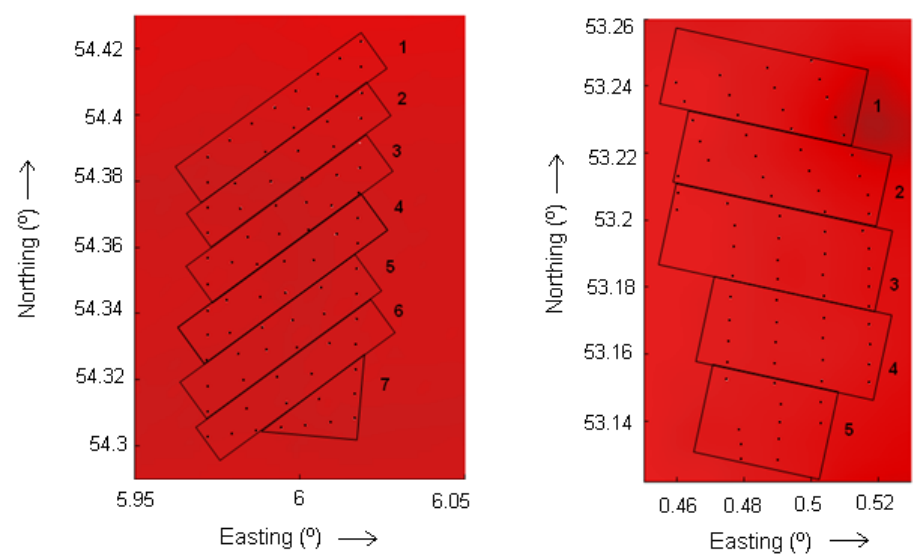

Figure 3. The $j$-th areas into which Bard 1 (left) and Lincs (right) were divided to calculate the $H R A_{j}$ index. 

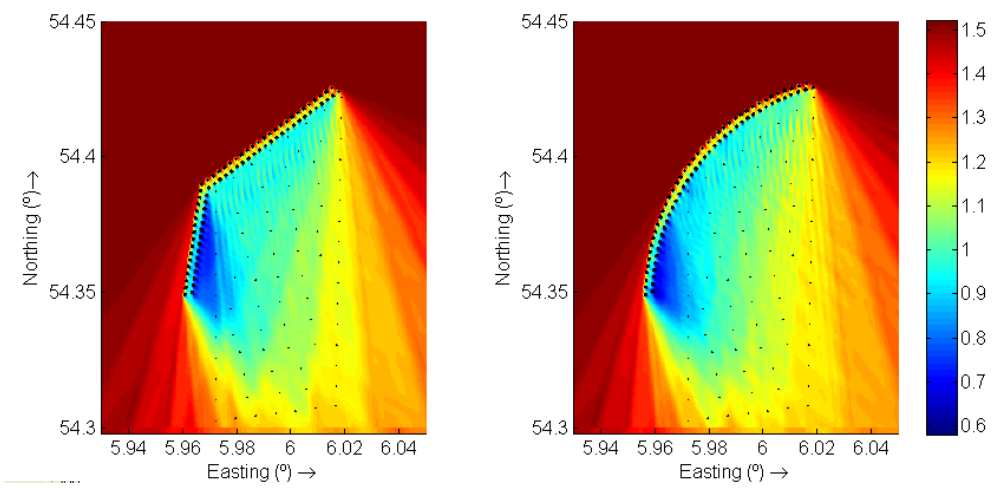

Figure 4. Wave height reduction obtained with co-located WECs at Bard 1 under a sea state with: $H s=1.71 \mathrm{~m}, T p=6.09 \mathrm{~s}$ and $\theta=230^{\circ}$. The colour scale represents the significant wave weight, $H s(\mathrm{~m})$. 

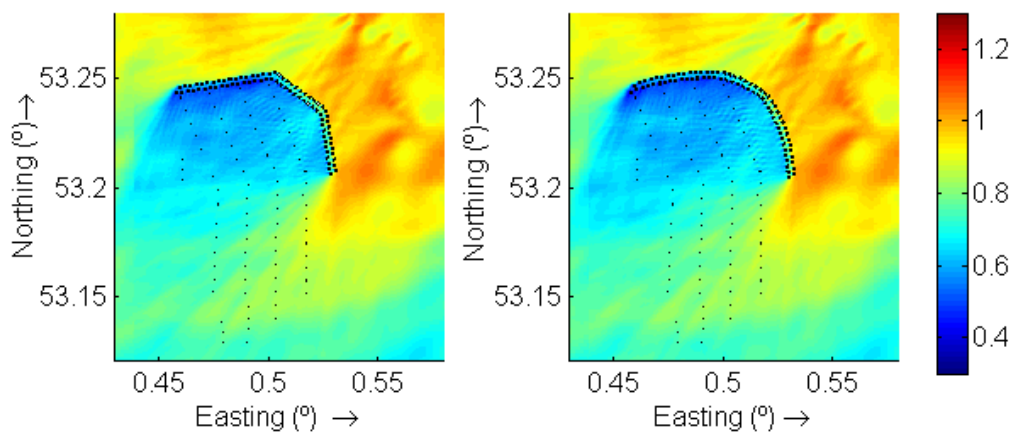

Figure 5. Wave height reduction due to co-located WECs at Lincs under a sea state with: $H s=1.18 \mathrm{~m}, T p=6.03 \mathrm{~s}$ and $\theta=60^{\circ}$. The colour scale represents the significant wave weight, $H s(\mathrm{~m})$. 


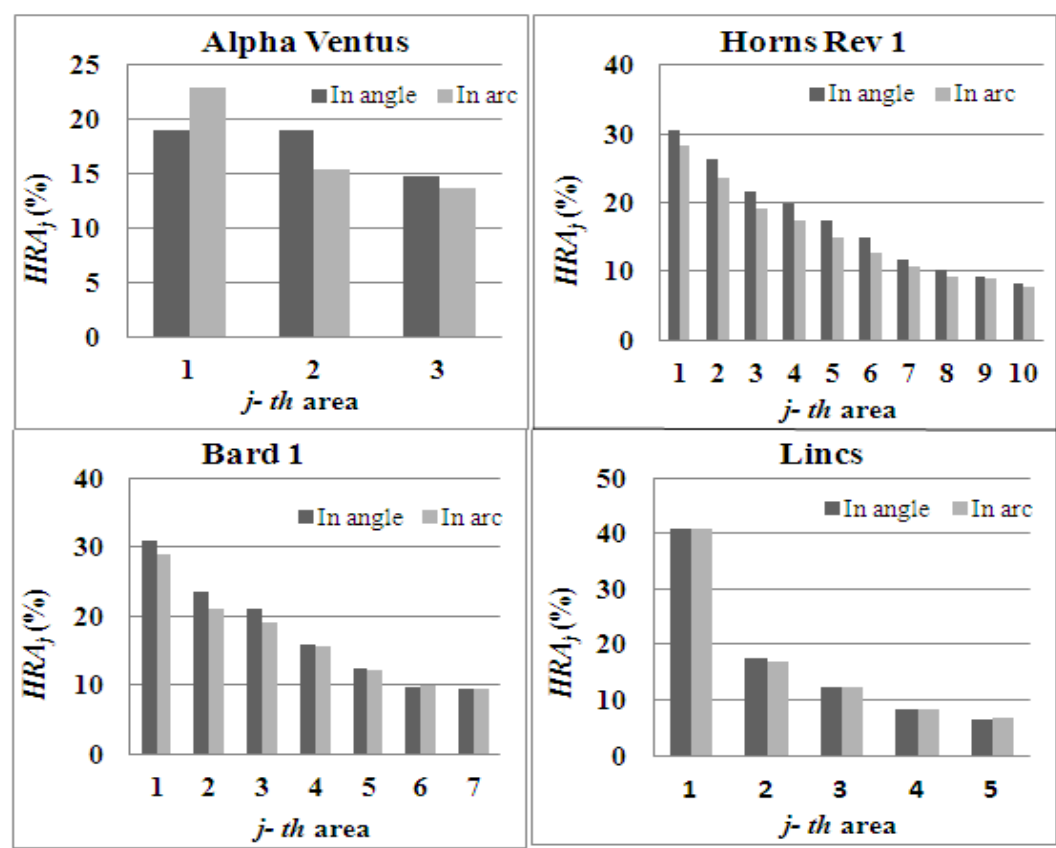

Figure 6. HRAj (\%) values with co-located WECs deployed in angle or in arch based on the annual data series data. 
Table 1. Characteristics of the Wind Farms

\begin{tabular}{cccccc}
\hline Wind farm & $\begin{array}{c}\text { Depth } \\
(\mathrm{m})\end{array}$ & $\begin{array}{c}\text { Distance from } \\
\text { shore }(\mathrm{km})\end{array}$ & $\begin{array}{c}\text { Installed capacity } \\
(\mathrm{MW})\end{array}$ & $\begin{array}{c}\text { Number } \\
\text { turbines }\end{array}$ & $\begin{array}{c}\text { Area } \\
\left(\mathrm{km}^{2}\right)\end{array}$ \\
\hline Alpha Ventus & $33-45$ & 56 & 60 & 12 & 4 \\
Bard 1 & $39-41$ & $90-101$ & 400 & 80 & 59 \\
Horns Rev 1 & $6-14$ & $14-20$ & 160 & 80 & 21 \\
Lincs & $8-16$ & 8 & 270 & 75 & 41 \\
\hline
\end{tabular}


Table 2. Wave and Wind Conditions at the Wind Farm Site.

\begin{tabular}{cccccc}
\hline Wind farm & $H_{s}(\mathrm{~m})$ & $T_{m o l}(\mathrm{~s})$ & $\theta\left(^{\mathrm{o}}\right)$ & $U_{w}\left(\mathrm{~ms}^{-1}\right)$ & $D_{w}\left(^{\circ}\right)$ \\
\hline Alpha Ventus & 1.5 & 4.6 & 330 & 10 & $210-240$ \\
Bard 1 & $0.8-1.5$ & 4.0 & 320 & 9.2 & 330 \\
HornsRev 1 & $0.8-1$ & $4-4.6$ & $230-340$ & 9.7 & $225-315$ \\
Lincs & $0.6-0.7$ & $3.4-4.4$ & $0-15$ & 8.4 & $10-70$ \\
\hline
\end{tabular}


Table 3. Total Number of Co-located WECs and the Rate Between the Total Number of WECs and Wind Turbines $(r)$.

\begin{tabular}{ccccc}
\hline \multirow{2}{*}{ Wind farm } & \multicolumn{2}{c}{ Layout in angle } & \multicolumn{2}{c}{ Layout in arch } \\
\cline { 2 - 5 } & Total & $r$ & Total & $r$ \\
\hline Alpha Ventus & 34 & 2.83 & 32 & 2.67 \\
Bard 1 & 79 & 0.99 & 79 & 0.99 \\
Horns Rev 1 & 55 & 0.69 & 53 & 0.66 \\
Lincs & 81 & 1.01 & 80 & 1 \\
\hline
\end{tabular}


Table 4. Surface Area Covered by the Computational Grids and Grid Size.

\begin{tabular}{lcccc}
\hline \multirow{2}{*}{ Wind farm } & \multicolumn{2}{c}{ Coarse grid } & \multicolumn{2}{c}{ Nested grid } \\
\cline { 2 - 5 } & Area $(\mathrm{km})$ & Resolution $(\mathrm{m})$ & Area $(\mathrm{km})$ & Resolution $(\mathrm{m})$ \\
\hline Alpha Ventus & $40 \times 30$ & $100 \times 100$ & $8.5 \times 8.5$ & $17 \times 17$ \\
Bard 1 & $111 \times 111$ & $222 \times 222$ & $18 \times 22$ & $40 \times 40.4$ \\
Horns Rev1 & $42 \times 32$ & $70 \times 80$ & $9.35 \times 9$ & $17 \times 20$ \\
Lincs & $119 \times 111$ & $170 \times 159$ & $14.4 \times 18.2$ & $32 \times 33$ \\
\hline
\end{tabular}


Table 5. HRF (\%) Values achieved with co-located WECs deployed in angle or in arch based on the annual data series.

\begin{tabular}{cccc}
\hline Wind farm & Layout & $N_{W E C S}$ & $H R F(\%)$ \\
\hline \multirow{2}{*}{ Alpha Ventus } & in angle & 34 & 18 \\
& in arch & 32 & 17 \\
\hline \multirow{2}{*}{ Bard 1 } & in angle & 79 & 19 \\
& in arch & 79 & 17 \\
\hline \multirow{2}{*}{ Horns Rev 1 } & in angle & 55 & 17 \\
& in arch & 53 & 15 \\
\hline \multirow{2}{*}{ Lincs } & in angle & 81 & 14 \\
& in arch & 80 & 13 \\
\hline
\end{tabular}


Table 6. Accessibility and $\Delta \mathrm{T}_{\mathrm{O} \& \mathrm{M}}$ Values for the co-located farms considered.

\begin{tabular}{cccc}
\hline Wind farm & Layout & Accessibility $(\%)$ & $\Delta T_{O \& M}(\%)$ \\
\cline { 2 - 4 } Alpha Ventus & in angle & 82.3 & 18.0 \\
\cline { 2 - 4 } & in arch & 82.2 & 17.8 \\
\hline \multirow{2}{*}{ Bard 1 } & in angle & 69.7 & 18.2 \\
\cline { 2 - 4 } & in arch & 69.0 & 17.5 \\
\hline \multirow{2}{*}{ Horns Rev 1 } & in angle & 70.9 & 15.6 \\
\cline { 2 - 4 } & in arch & 69.5 & 13.9 \\
\hline \multirow{2}{*}{ Lincs } & in angle & 81.3 & 8.9 \\
\cline { 2 - 4 } & in arch & 81.1 & 8.6 \\
\hline
\end{tabular}

